\title{
On the types of assessments concerning the effectiveness of medical procedures'
}

\author{
Włodzimierz Galewicz
}

Zakład Badań nad Etyką Zawodową, Instytut Filozofii, Wydział Filozoficzny, Uniwersytet Jagielloński

Address for correspondence: Włodzimierz Galewicz, Zakład Badań nad Etyką Zawodową, Instytut Filozofii, Wydział Filozoficzny, Uniwersytet Jagielloński, ul. Grodzka 52, 31-044 Kraków,w.galewicz@uj.edu.pl

\section{Abstract}

The subject of this article is the assessment of the effectiveness of medical procedures or interventions. In its first part I compare the different meanings that the term effectiveness assumes in the context of assessing medical interventions, including the definition of the concept of consequential effectiveness, i.e. efficiency in achieving a certain objective of recognized value, distinguishing it from purely instrumental efficiency, i.e. effectiveness in achieving any goal, and from 'cost-effectiveness' or economic efficiency. Next, I discuss various directions of relativization that allow for, and largely assume, assessments of the effectiveness of medical interventions, primarily considering the purpose, which serves as their point of reference. In the third part, I emphasize the different character of assessments of the effectiveness of medical procedures depending on whether they relate to the final or only to the indirect purpose of a given procedure. Finally, I consider the validity of the popular opposition of effectiveness and efficiency, and egalitarian fairness or justice (equity) in relation to health care procedures.

Key words: medical procedures, goals of healthcare, health henefits, effectiveness, efficiency, appropriateness, enuity

Stowa kluczowe: procedury medycczne, cele opieki zulrowotnej, korzyści zulrowotne, efektywność, stosowność, eyalitarna równość

\section{1}

The decision about the allocation of health resources is based on different types of assessments of medical procedures. ${ }^{2}$ Undoubtedly, one type of assessments of medical procedures or technologies that is significant - or indeed crucial - for the resource allocation is the assessment of effectiveness. However, the meaning which is attributed in this context to effective medical interventions is less obvious: are they to be understood as activities that serve the accomplishment of a certain goal, whose value does not have to be assumed by the evaluating entity, or as procedures that are effective in the implementation of certain goods appreciated and valued by the entity, and if so, which ones.

Medical procedures or healthcare services can be assessed from several different viewpoints. First of all, they can be evaluated taking into account the suitability and the rank of their purpose, i.e. because of their own suit- ability and teleological validity. For example, a low or even negative assessment of cosmetic surgery as one of the technically feasible healthcare services is often due to the belief that enhancing the appearance is not a legitimate purpose of medicine, and even if it falls within its scope, it takes a subordinate position. ${ }^{3}$

Having established the internal purpose of a given kind of medical procedure, as well as its suitability and rank, one can evaluate the procedure taking into account three other features, each of which is sometimes ambiguously referred to as effectiveness. Firstly, medical procedures - just like any other intentional actions - can be evaluated taking into account the effectiveness with which they fulfil their goal, i.e. the aspect of their instrumental efficiency. Secondly, they are evaluated in terms of their consequential effectiveness, in particular the utilitarian aspect, i.e. looking at the value of their desired result (especially the benefit that results from them). Thirdly, medical procedures may also be subjected 
to (simple or comparative) assessments due to their economic (or 'cost') effectiveness, i.e. the ratio of the value of their results to the amount of their costs. Let us take a closer look at these three concepts.

The assessment of instrumental efficiency, i.e. the effectiveness of an action, takes into account whether and to what extent the assessed activity achieves its purpose, and so realizes the intended effect. The subject of this type of assessment may be both individual activities and entire types or categories of activities having a specific goal or set of objectives. When assessing the effectiveness of a certain type of activity, the average effectiveness of individual activities belonging to this type is taken into account.

An important feature of assessments determining the instrumental efficiency of certain medical procedures - if it is understood only as such, i.e. captured in its pure form - is their ethical neutrality. Therefore, the assessment of the purely instrumental efficiency of a procedure affirms only whether and to what extent the assessed form of action is effective in achieving a possible or actual goal, without prejudging whether this possible or actual goal is also desirable or worth pursuing. Such ethically neutral understanding of effectiveness is also possible in relation to medical activities. For example, the effectiveness of different sterilization methods for men can be evaluated also by someone who does not think that men should be sterilized. Similarly - although it may not be necessarily worthwhile - the effectiveness of different types of screening for Down's syndrome may be compared, taking into account their effectiveness in achieving the possible goal of reducing the number of children born with the syndrome, without prejudging whether the number of children born with the syndrome should be reduced, and whether it should be done via abortion, which sometimes, though not always, is a result of a positive result of specially adapted prenatal tests. ${ }^{4}$

The ethical neutrality that is part of the purely instrumental effectiveness of medical procedures cannot - by its very nature - be maintained in those assessments that determine their consequential or economic effectiveness. What these two types of assessments have in common is that they incorporate the concept of benefit (already imbued with positive meaning): the former is to determine the overall benefit - or the total value of partial benefits - that can be obtained through a given procedure; the latter is to determine the connection between the benefits obtained through a given procedure (or additional benefits) and related costs (or additional costs). In both cases, however, the amount (value) of benefits that certain procedures generate depends also on the value of their objective, and not only on the extent or degree in which they implement it.

Assessment of an action's instrumental effectiveness is an assessment of its effectiveness in achieving a certain goal, whose value, significance or weight is not assumed in the assessment itself. If the goal we evaluate a given activity for is considered valuable or important, then the subject of our assessment is also the consequential effectiveness of this activity. The consequential effective- ness of an action depends on how important the objective is and how efficiently or to what extent this goal is achieved through this action. Therefore, the assessment of consequential effectiveness of an action is - in essence - a complex evaluation, assuming or containing the two forms of simpler assessments indicated above.

If the assessment of consequential effectiveness of medical procedures includes mainly or exclusively their health benefits, the established effectiveness is also called clinical effectiveness. Understood in this way, clinical effectiveness is further divided into effectiveness that some intervention shows under ideal conditions of clinical trials, i.e. experimental effectiveness (or efficacy), and the effectiveness - often diverging from efficacy - which this same intervention (generically) has in real medical practice, i.e. practical effectiveness (or simply effectiveness). ${ }^{5}$ The clinical effectiveness of medical interventions -both in its practical and experimental aspects - is sometimes understood in a slightly narrower sense, where it is contrasted with safety or harmlessness. For example, the therapeutic value of a medicine depends both on the probability with which it allows to achieve desired effects and on whether it is associated with an excessive risk of negative consequences or 'side effects'. However, it can be assumed that an effective medical intervention should fulfil both the positive aim (to bring improvement) and the negative aim (not to cause harm). Understood in this way, the effectiveness of the medical procedure is implicitly safe, harmless and unburdensome.

Having established - on the one hand - the value of the result and, on the other, the cost of the medical procedure, its profitability or economic efficiency, also called cost-effectiveness, can be assessed. The principle of economic efficiency is that we should proceed in such a way as to achieve the best result at the lowest possible cost. Therefore, having at your disposal a certain resource, you should use it to achieve the best result; and having to achieve a certain result, you should accomplish it with the least possible amount of funds. In the case of a procedure stretched over time, its costs can include not only the funds launched for its implementation (e.g. resources needed to carry out an operation), but also those used during its implementation, and sometimes even after its completion (e.g. costs of treating the adverse consequences of the procedure).

Let me complement these initial remarks on the various ways of understanding the concept of effectiveness with a comment: all the meanings of the term contain a harmless, but sometimes deceptive, ambiguity, which is also characteristic of many other elements of the vast category of abstract nouns derived from adjectives to which it belongs. Another example of a similarly 'indeterminate' concept may be that of lightness, including when it is used to describe the colours. In one sense, the lightness of colours means a certain aspect or 'dimension' available to all colours. All colours can be described in terms of lightness, distinguishing among them more or less light, as well as light and dark. Even the dark colours, however, have a certain lightness in this wider sense, in that they are somehow defined in terms of lightness, whereas the 
lightness of colours in a narrower sense means a feature that distinguishes the light colours from dark ones, and is therefore only attributed to the colours perceived as sufficiently light. The same applies to effectiveness. In a broader sense, the effectiveness of an action is a feature that is attributable to all activities with a specific purpose, performed in a better or worse fashion, more effectively or less so. In a narrower sense, however, the effectiveness of an action is a trait that serves to distinguish between effective and ineffective actions, i.e. it is attributed only to the actions evaluated as effective or effective enough. Apart from the effectiveness of medical interventions in the sense of the most general feature or 'aspect', which we have in mind when distinguishing effective and ineffective interventions, or effectiveness in the sense of a feature that serves to distinguish those interventions that are effective to a sufficient degree (or to a degree higher than the average), there is a third, somewhat indirect, meaning of effectiveness. In its consequential understanding, this effectiveness is also referred to as appropriateness, and is typical of medical interventions that are minimally effective, in that they bring at least slightly more benefit than damage. According to the definition provided by Park et al. [4], when describing a medical procedure as appropriate, we state that "the expected health benefit (i.e. increased life expectancy, relief of pain, reduction in anxiety, improved functional capacity) exceeded the expected negative consequences (i.e. mortality, morbidity, anxiety of anticipating the procedure, pain produced by the procedure, time lost from work) by a sufficiently wide margin that the procedure was worth doing."

\section{2}

Both instrumental and consequential effectiveness of certain medical interventions consist in their effectiveness in the implementation of an indicated or assumed goal. On some occasions, this particular goal that we evaluate a given intervention for, is already 'inscribed' into the concept itself, so that it does not have to be given separately; for example, it is not necessary to state what purpose effective analgesia or effective life-saving surgery have, because we know that the goal of the latter is to save lives, while the former serves to prevent pain. Often, however, medical intervention can realize - or has to simultaneously pursue - several different goals, but its effectiveness in their implementation can be diversified; for example, acupuncture may be effective - to some extent - as a method of relieving pain or nausea, but ineffective as an alleged (and publicised) way of "strengthening the body".

Even after defining the objective, in view of which the given action is assessed as instrumentally or consequentially effective, this assessment requires even more (and manifold) relativization. The very same (abstractly speaking) action or procedure can achieve its goal effectively or ineffectively, or more or less effectively depending on who performs it, on whom it is performed, as well as the manner or circumstances in which it is performed.
This manifold relativization - whether clearly formulated or only implicitly understood - is also needed in the case of an assessment of the effectiveness of medical interventions.

Firstly, therefore, the effectiveness of a medical procedure will often and to a large extent depend on who the operation is performed by. The widely understood medical interventions may be performed by healthcare workers - a doctor, a nurse or a paramedic - but also the patients themselves. The physician performing the operation or interpreting the results of diagnostic tests may be better or worse educated and qualified, experienced to varying degrees, and more or less efficient at a given moment. Also the patient who is to regularly take the prescribed medicine or perform the recommended exercises will be more or less patient, determined and disciplined (usually less rather than more). Most medical interventions, however, require a patient's cooperation, not just their consent to the procedure. If the patient does not perform his / her part of the 'job', the part performed by the medical staff may in the end go to waste; for example, the screening tests for Alzheimer's disease make little sense if the patients who have worrying symptoms generally do not report for further tests.

Secondly, the effectiveness of a medical intervention depends on whom, or what patient or group of patients, it is performed. The same intervention, which in a broader category of people (e.g. suffering from cancer of an organ) is statistically ineffective, can be much more effective when it is more precisely 'targeted', i.e. applied to patients belonging to a narrower category (e.g. cancer with a specific genetic basis). What is true of the effectiveness of medical interventions is of course true of their safety or harmlessness: the same therapy, which for most patients is statistically rather safe, may be very harmful for a certain group of people.

Thirdly, the effectiveness of a given medical procedure is always - and to some extent - dependent on how this procedure is performed. The degree of this dependence may be higher or lower. If it is high enough - as when a procedure can be performed not only in a more or less efficient way, but also correctly or incorrectly - it could even be the reason for distinguishing between the abstract scheme of a given procedure (which we could then call 'medical technology') and more specific 'medical interventions' where this technology is used.

All the directions of relativization presented above, which must complement the assessment of the effectiveness of medical interventions, also provide the basis for distinguishing two main variants of this type of effectiveness which in English is often communicated through separate terms. Taking into account the dependence of the effectiveness of an action on the efficiency of the person who performs it, the properties of the person it concerns, and the way it is performed, efficacy and effectiveness are juxtaposed in relation to medical procedures or technologies. ${ }^{7}$ The experimental effectiveness - effi$c a c y$ - of a tested medicine means its capacity to induce the intended effects under ideal conditions which are ensured in clinical trials, while its (practical) effectiveness 
is understood as the capability to cause these effects in medical practice. For example, the same drugs that are highly effective when applied at appropriate doses and at appropriate intervals by specialists during clinical trials may be much less effective when administered by the patients themselves ${ }^{8}$.

\section{3}

When assessing the effectiveness of a medical intervention, its goal must always be considered, yet it is not always quite clear what it is. Medical interventions have different goals, closer and further. For example, the closest goal of prophylactic statin use is to lower the blood cholesterol, a slightly further goal is to prevent atherosclerosis, and even further still is to reduce the risk of heart attack or stroke, for example, but this aim of a long-term prophylactic intervention is still only an indirect goal. Indirect goals of medical interventions form a sequence that leads to some final goal. The final or ultimate goal is always a certain aspect of health, good life or well-being, either a rather specific aspect (e.g. avoiding premature death due to heart disease), or quite general (how to protect yourself from premature death caused by any reason). When examining the comparative effectiveness of various alternative medical interventions, it is clearly easier to compare their effectiveness in achieving a close, immediate objective (e.g. by checking how effectively different types of statins lower cholesterol). However, as has been repeatedly stated, these indirect goals included in the assessments of the effectiveness of medical interventions, can only function as surrogate endpoints ${ }^{9}$. The assessment of the effectiveness of medical interventions in the implementation of a certain surrogate end-point is unreliable, and, in fact, not very interesting until we establish a close correlation between this surrogate end-point and some specific aspect of the final goal (true end-point). The closeness of this correlation, and sometimes even its very existence, is sometimes questioned or 'contested'. For example, in the case of the 'cholesterol dispute' that has been going on for years, some people have said that even if statins lead to a reduction in blood lipids, it remains unknown whether it prevents atherosclerosis, and even if it does prevent atherosclerosis, it remains unknown whether it reduces the risk of death due to heart disease, and even if it reduces the risk of death from heart disease, it remains unknown whether it reduces the risk of death occurring due to any other reason [12]. In this situation, when assessing the effectiveness of medical interventions, it would be safest to take into account their final goals. Unfortunately, these principled assessments of medical procedures are often difficult, for several reasons [13]. Firstly, even if we have serious reasons to believe that realizing the indirect goal of medical intervention is - to some extent - conducive to achieving its ultimate goal, it is often difficult to determine the exact extent; meanwhile, without this quantitative evaluation it is impossible to establish a comparative effectiveness of medical interventions that serve various closer or indirect objectives. Secondly, in order to assess the effectiveness of medical interventions in relation to their ultimate or final goals, we often have doubts as to which of the possible goals of a given intervention should be considered ultimate or final; for example, we may hesitate whether the ultimate goal of prenatal testing towards Down's syndrome can also be the mere awareness of a woman that her child will be burdened with this disadvantage, regardless of whether this awareness is necessary for her or whether it will affect her practical decisions. Thirdly, there are various aspects of health, good life or well-being that are suitable final goals of medical interventions, so that even if we determine that the assessed intervention has a positive effect on one of these aspects (e.g. freedom from pain), we do not often have the certainty that it does not cause a negative effect on another (e.g. level of consciousness).

The scope of the final goals of medicine or health care can be delimited more extensively or less so. In its narrowest form, it covers everything which contributes to human health or a healthy life (and only that): well-being, efficient functioning or living to an age when death is not said to have come too early. In a somewhat broader sense, the scope of the ultimate goals of medicine - the final goals of human endeavours that can be implemented to some extent with the help of skills, means and medical actions - also includes elements of human well-being or happiness, which are generally considered different and relatively independent of health. This 'extra', healthunrelated element of well-being, can be even satisfaction with one's appearance, regarded as the legitimate aim of aesthetic surgery, or acceptance of one's sexual constitution, which at times can only be achieved by a sex reassignment surgery. Even more broadly, the sphere of actual and ultimate goals of medicine is defined when it includes such goods as autonomy, freedom or knowledge - goods that are generally not considered to be elements of happiness or well-being, but as 'non-welfare' values. However, way beyond the limits of medical utilitarianism or welfarism goes the concept including not only the goods of the person - related to health, or not - but also some interpersonal or situational goods, ${ }^{10}$ such as a fair or even distribution of certain goods that are retained or recovered through medical care.

The distinction between indirect and final objectives of medical interventions is particularly important when opposing complex and simple interventions. Some medical or health-related interventions are limited to one relatively simple operation, such as when someone is taking a pill to relieve a headache. Most medical interventions, however, are complex interventions that include many consecutive (and sometimes co-occurring) component activities, either homogeneous or heterogeneous. Various activities that are part of a complex intervention are usually used to accomplish a certain subordinate or indirect goal, which, however, makes sense only as long as it is a means to implement the overriding objective of the whole procedure. For example, screening for Alzheimer's disease, or non-invasive (and therefore inconclusive) prenatal testing for Down's syndrome is in itself the only non-independent stage of a more extensive 
diagnostic process; they can, therefore, be truly effective only if their possible positive results are confirmed or refuted by a definitive or proper diagnosis (e.g. chorionic villus sampling and amniocentesis with suspected Down syndrome or by complex neurological examinations for symptoms indicative of Alzheimer's disease). However, the non-independent element of a more comprehensive medical procedure is often its main or the most difficult stage, as it is with transplant surgery, which in itself could be the most successful and yet ineffective (or even 'counter-effective') in achieving its final goal if the transplant recipient does not receive appropriate immunosuppressive medicine.

An example of an intervention consisting of many homogeneous parts could be a series of injections, any longer pharmacological treatment, or a series of meetings with a psychotherapist. The final purpose of such intervention can be implemented either gradually by individual actions (such as successive injections), or achieved only after the appropriate number of them has been performed. Also an indirect situation is possible, when individual elements or subsets of elements of a complex medical procedure accomplish successively its various partial goals (as in the case of psychotherapy, whose subsequent, deeper goals are to be implemented by appropriate 'doses' of meetings with the therapist). ${ }^{11}$

\section{4}

The effectiveness of medical interventions is often mentioned as one of its two principal qualities, sometimes co-occurring, but often colliding with the no-lessfundamental quality of egalitarian justice. This opposition - in English captured by the terms effectiveness (or efficiency) and equity [16] - is undoubtedly justified if it refers to utilitarian effectiveness, or to effectiveness in implementing the welfarist good. The utilitarian principle of maximizing the sum of individual benefits achieved in the dimension of well-being or good life must indeed collide with the idea of their most equal distribution between different individuals or groups of people. However, as already pointed out, utilitarian effectiveness, and in particular the effectiveness in realizing individual health benefits, is only one of the varieties of the broadly understood consequential effectiveness.

Suppose we are to divide a limited number of medical resources between two groups of people - for example, residents of two different regions - whose populations are more or less equal, but which differ in their health condition and the resulting life expectancy: in the first group it amounting to the average 70 years of age, while in the second - only 65 . And suppose we have to choose and start the implementation of one of two promising health programs. Program A will be intended for the members of the first, 'better-performing' group, and according to rational estimates (as it can be unrealistically assumed), it will increase their average life expectancy by 5 years, raising it to 75. Program B will be intended for members of the second, worse-performing group and, according to equally valid calculations, will also increase their average life expectancy by 5 years, raising it to 70 . If the second program, intuitively fairer, does not outweigh the first under any medically significant aspect - for example, guaranteeing a greater improvement of the quality of life to its potential beneficiaries - then, on the basis of utilitarianism, we have no reason to grant it superiority. The first program would not give way to the second in terms of consequential effectiveness, measured according to utilitarian rules. And if we were to assume that - as a result of its implementation - the average life expectancy in the better-performing group would increase even slightly more, e.g. by 5.5 years, then it would also have an ethical advantage over the other. Can these rather disconcerting conclusions be avoided in some way, without going beyond the limits of consequentialism, in its broader sense?

Well, it can be shown that there is a way, and - formally speaking - it is twofold. The outlined problem concerns the assessment of medical interventions in terms of their effectiveness, which I propose to be defined as consequential. This terminological suggestion seems justified also due to the fact that the task of these assessments is precisely to say to what extent the considered intervention satisfies the normative theory of consequentialism. The central thesis of this theory is the norm also referred to as the principle of maximizing good. It tells us that in every situation we should act in a way that (at least according to rational prognoses) leads to the best result, or to put it more clearly: to the result of the highest ethical value. The result of the action, on which consequentialists focus their attention, is usually associated with the total sum of consequences (hence the name), although sometimes it is also extended to the action itself (its internal value may be an important component of the total value of the complete result). When assessing the result of an action, we can limit ourselves to its consequences, which have a certain internal value, and therefore only take into account the consequences that are good or bad in themselves (as all remaining consequences will be counted anyway, since they contribute to this internal value).

The principle of consequentialism requires us to proceed in every situation in a way that will (probably) result in consequences of the highest total internal value. The command as such - the obligation to maximize the good - is, however, of a very general and rather formal nature. It does not determine what can be attributed an intrinsic value or what it is based on. In other words, it specifies neither the carriers of internal value nor its criteria. Utilitarianism attempts to fill both gaps by introducing two further principles. First of all, it assumes that the carrier of a positive internal value can only be a good belonging to the person or person's life - something whose possession or experiencing makes the person's life better than it would be without having or experiencing it. Since in English the good life of a person is also often referred to as welfare, or well-being, this first peculiar thesis, which distinguishes utilitarianism from other varieties of consequentialism, can be called the principle of welfarist goods. Secondly, utilitarians assume that the inner value of the good of the person can only depend or be 
based on something that - through being owned or experienced - makes the person's life somewhat better (more satisfactory, happy, successful) than it would be otherwise. And so, if something that gives value to something else is regarded as the criterion of this value, this second thesis of utilitarianism can be defined as the principle of welfarist criteria. According to the principle of welfarist goods, the only final benefit that can result from a certain medical intervention is the improvement of the value of a person's life, either by increasing its welfaristic quality or by increasing its length (assuming that its welfaristic quality is not too low, and so that it would be worth extending). According to the principle of welfarist criteria, the value of the benefit that a person derives from a certain medical intervention does not depend on anything other than the greatness of this benefit - the greater, the more the intervention improves the welfarist quality of life of the person or increases its length. Assuming, then, that the value of a certain life benefit does not depend on anything other than its greatness (in the given sense), the principle of welfaristic criteria recognizes, among other things, that it is not dependent on who benefits from it or when they benefit from it, or any other circumstance that is not related to the greatness of the benefit itself. In other words, the principle of welfarist criteria - despite its clearly non-utilitarian implications - yields a particular demand for equality: as it imposes that equal weight be granted (and, as a result, equal value) to equally great life benefits experienced by different people (or the same person at various stages of their life).

As it is not difficult to notice, it is this pair of utilitarian premises, concretizing the consequentialist principle of maximizing good, which leads to intuitively unacceptable conclusions drawn from the example of the two programs presented above. Since the only or decisive reason for favouring one health program over another is the greater sum of benefits that the first provides, and since the benefit derived from the program by the inhabitants of the region with a longer life expectancy is (at least) equal to that which is drawn by the residents who live shorter, we have no reason not to assign it - or actually we do have a reason to assign it - on preferential terms to help the first group. At the same time, however, the same simple example allows us to realize how one can waive this conclusion, difficult to accept due to its incompatibility with even the most basic egalitarianism. One of the strategies that comes to mind here is, of course, the question of challenging the exclusive validity or even supreme role of the principle of maximizing good, and therefore recognizing that this consequentialist rule is only one of the equivalent principles defining our duties, which are supplemented and often contested - by other leading norms, such as the principle of respect for autonomy, or - importantly for the example we are discussing - the principle of egalitarian justice. This deontological pluralism, or at least duality, is assumed when consequential or economic efficiency (effectiveness or efficiency) is contrasted with egalitarian justice (equity). In addition to this solution, which entails a complete break with consequentialism, two somewhat more conciliatory solutions can be proposed. In the ex- ample presented, one of them is based on the assumption that the individual health benefits received by the beneficiaries of the aid program for residents with a shorter life expectancy - i.e. the additional years of life they obtain - do not constitute all the benefits of the program. To these individual or personal benefits one must add an interpersonal benefit, which is the removal of inequalities that existed so far between the two groups of residents: if before receiving additional medical help, the inhabitants of the second region lived on average 5 years shorter than the inhabitants of the first region, after receiving the aid program the average life expectancy will be the same. The second consensual solution, allowing its supporters to remain within the theory of consequentialism, but avoiding the utilitarian paradoxes, is based on the assumption that even if the benefits of alternative health programs boil down to additional years of life obtained by their beneficiaries, these life benefits for the region's inhabitants with the smaller life expectancy in the final and complete assessment have a greater value than the benefits of residents who live longer; even though the benefit of the inhabitants of the first region has the same statistical value as the advantage enjoyed by the inhabitants of the second region, the value of these benefits is not equal: 5 additional years of life for a person whose life would be shorter without obtaining aid, has more value than the same (speaking of its welfaristic quality) 5 years of life for a person who would live longer without aid.

Observations arising from the given example can be generalized. The non-intuitive consequences to which standard utilitarianism leads in the ethics of distribution, and in particular the allocation of health resources, do not arise from the general principle of maximizing good, shared with other variants of widely understood consequentialism, but result from a pair of its specifications: the principle of welfarist goods, defining the range of goods which are entitled to internal value, and the principles of welfarist criteria, indicating the foundation of the value of these goods. Both of these principles can be rejected or modified, while adopting the perspective of some type of consequentialism, albeit not utilitarian, yet extended or supplemented. It's one version will be the concept of additional goods, expanding the range of goods that require maximization with certain non-welfarist or even non-personal goods, such as the situational good of social equality in the distribution of benefits, without increasing (or reducing) the sum of these benefits. It can also be said that by expanding the range of goods that should be included in the assessment of the benefits of a given medical intervention, this first concept also extends the very notion of benefits, as - in addition to individual health benefits - it recognizes the related, but not equivalent, social benefits, which - as in the example of equalizing the average life expectancy in two population groups - also deserve to be called 'health benefits' and require taking into account the effectiveness of medical interventions. The second version of the modified consequentialism, which in practice may lead to the same decisions as the first, but from a theoretical point of view occupies a separate position, is the concept of ad- 
ditional criteria. In contrast to the concept of additional goods, it does not extend the scope of benefits requiring to be taken into account in assessing the effectiveness of a procedure, but points to additional, non-welfaristic factors determining their value; for example, the value of an advantage that a person derives from a life-extending therapy may be dependent not only on the number of years he or she continues to live, but also on how long or short-lived they would be without this therapy.

If we accept one of the presented versions of extended consequentialism - i.e. if we recognize either the additional goods that may constitute the benefits of medical interventions, or additional criteria, co-determining the value of these benefits - then effectiveness in health care should not be contrasted with egalitarian justice since it is already contained in it.

\section{Notes}

1 The following article is related to my research project titled "Justice in healthcare", financed by the National Science Centre as part of the Maestro 4 competition.

${ }^{2}$ Medical procedures - the term included in the title of this article - is only a convenient mental shortcut, replacing the longer enumeration of medical procedures or medical technologies, or health programs, or strategies in health care etc. - all these forms of action can be evaluated in terms of their effectiveness.

3 See, for example [1]. Another example is the relatively low - third before last - position of infertility treatment in the ranking of health services containing 17 degrees of importance and developed in the second phase of the health system reform in the State of Oregon. This low position, of course, did not result from the assessment of the effectiveness of this category of services, which - depending on the technique used - can have extremely varied effectiveness, measured by the number of cases of successfully initiated and successfully finalized pregnancies. Rather, it resulted from the low rank assigned to the purpose of these benefits, that is, the reproduction itself, because of the three criteria of importance adopted by the committee: value for basic health care, value for society and value for the individual in need of those benefits [2].

${ }^{4}$ Gilbert et al. [3] compare different types of screening tests for Down's syndrome, assessing their safety, efficiency and cost effectiveness. Efficiency is effectiveness in achieving the intended goal but it is not clear what is to be considered the exact goal of prenatal screening tests. The authors take into account the 'social perspective', according to which the goal would be to "maximize health gain for a given cost" which probably should be understood as being able to achieve - through a given cost - the highest quality of life for women or parents, which would inevitably drop after having a child with Down's syndrome - but they consider this concept problematic (p. 4). Themselves, they assume that when assessing the effectiveness of the analyzed types of screening tests, their effectiveness in achieving the goal of preventing the birth of a live child with Down's syndrome should be taken into account. Based on empirical data, they conclude that the two most economically effective ways to achieve this goal are the measurement of nuchal translucency and the integrated test. In the case of the former, carried out in a certain female population, the cost of preventing the birth of one live child with Down's syndrome was $£ 22,000$, while the cost of the latter amounted to $£ 51,000$.

${ }^{5}$ See below, footnote 7 .

${ }^{6}$ At other times, however, appropriateness can be distinguished from effectiveness on a different basis. Mandelblatt et al. [5] write that while effectiveness means "the impact of an intervention of health in real practice settings", appropriateness "reflects a broader range of issues considered in deciding whether an intervention should or should not be done, including acceptability, feasibility, and cost-effectiveness"; p. 552.

7 According to Haynes [6-8], the terms efficacy and effectiveness - the names of two values to be determined in the assessment of medical interventions - were introduced by the British pioneering epidemiologist Archie Cochrane, who added to them a third value, called cost-effectiveness. In his concise description, he reffered to the experimental effectiveness assessment as determining whether an intervention may work (“Can it work?"), i.e. bring more benefit than harm under ideal conditions, practical effectiveness assessment determining whether it works in practice ("Does it work in practice?"), and cost-effectiveness assessment answering the question of whether the benefits derived from this intervention are worth its cost ("Is it worth it?").

${ }^{8}$ For example, it has been pointed out that although neuroleptics for schizophrenic patients administered in the form of tablets may have the same clinical effectiveness as the same medicine administered in long-acting injections, which the patient receives during hospitalization, in practice are much less effective than the latter method, because some patients do not take them in the right doses or even shortly after discharge from the hospital, stop taking them entirely; Rynek Zdrowia, 19 listopada 2015 r., Eksperci: leki w iniekcjach to mniejsze koszty leczenia schizofrenii; http://www.rynekzdrowia.pl/Uslugi-medyczne/Eksperci-leki-w-iniekcje-to-mniejsze-kleszty-leczenia-schizofrenii,156900,8.html (accessed: 01.10.2017) [9].

9 See for example $[10,11]$.

${ }^{10}$ Regarding situational goods [14].

${ }^{11}$ See Howard et al. [15]. The authors distinguish three phases of psychotherapy - remoralization, remediation, rehabilitation - each of them defining a specific goal. In the first phase, it is the improvement of subjective well-being, in the second the alleviation of distressing symptoms, and only in the third more lasting improvement in life functioning.

\section{References}

1. Miller F.G., Brody H., Chung K.C., Cosmetic surgery and the internal morality of medicine, "Cambridge Quarterly of Healthcare Ethics" 2000; 9: 353-364.

2. Tragakes E., Vienonen M., Key Issues in Rationing and Priority Setting for Health Care Services, WHO/EURO Health Services Management, New York 1998.

3. Gilbert R.E., Augood C., Gupta R., Ades A.E., Logan S., Sculpher M., van Der Meulen J.H., Screening for Down's syndrome: effects, safety, and cost effectiveness of first and second trimester strategies, "British Medical Journal" 2001; 323: 1-6.

4. Park R.E., Fink A., Brook R.H., Physician ratings of appropriate indicators for six medical and surgical procedures, “Am. J. Public Health” 1986; 76: 766-772. 
5. Mandelblatt J.S., Fryback D.G., Weinstein M.C., Assessing the effectiveness of health interventions for cost-effectiveness analysis, "Journal of General Internal Medicine" 1997; 12 (9): 551-558. doi:10.1046/j.1525-1497.1997.07107.x.

6. Haynes B., Can it work? Does it work? Is it worth it? The testing of healthcare interventions is evolving, "British Medical Journal" 1999; 319: 652-653.

7. Marley J., Efficacy, effectiveness, efficiency, “Australian Prescriber" 2000; 23: 114-151.

8. Luce B.R., Drummond M., Jönsson B., Neumann P.J., Schwartz J.S., Siebert U., S.D., EBM, HTA, and CER: Clearing the Confusion, "Milbank Q" 2010; 88 (2): 256 276. doi: 10.1111/j.1468-0009.2010.00598.x

9. Rynek Zdrowia, 19 listopada 2015 r., Eksperci: leki $w$ iniekcjach to mniejsze koszty leczenia schizofrenii; http://www. rynekzdrowia.pl/Uslugi-medyczne/Eksperci-leki-w-iniekcjeto-mniejsze-kleszty-leczenia-schizofrenii,156900,8.html (accessed: 01.10.2017).

10. NICE (The National Institute for Health and Care Excellence), Guide to the methods of technology appraisal 2013; https:// www.nice.org.uk/process/pmg9/chapter/foreword, (accessed: 01.10.2017).
11. AOTMiT (Agencja Oceny Technologii Medycznych i Taryfikacji), Wytyczne oceny technologii medycznych (HTA), AOTMiT, Warszawa 2016.

12. Muldoon M.F., Manuck S.B., Matthews K.A., Lowering cholesterol concentrations and mortality: A quantitative review of primary prevention trials, "British Medical Journal" 1990; 301 (6747): 309-314.

13. Fleming T.R., DeMets D.L., Surrogate end points in clinical trials: Are we being misled? "Ann. Mem. Med." 1996; 125: 605-613.

14. Ross W.D., Foundations of Ethics. The Gifford Lectures, Oxford University Press, Oxford 2000.

15. Howard K.I., Mora K., Brill P.L., Martinovich, Z., Lutz W., Evaluation of psychotherapy: Efficacy, effectiveness, and patient progress, "American Psychologist" 1996; 51: 1059-1064.

16. Sassi F., Le Grand J., Archard L., Equity versus efficiency: a dilemma for the NHS: If the NHS is serious about equity it must offer guidance when principles conflict, "British Medical Journal" 2001; 323 (7316): 762-763.

Przygotowanie do wydania elektronicznego publikacji-zadanie finansowane w ramach umowy Nr 780/P-DUN/2017 ze środków Ministra Nauki i Szkolnictwa Wyższego przeznaczonych na działalność upowszechniająca naukę. 